\title{
A problemática dos resíduos em sistemas gelificados para a limpeza de pinturas
}

\author{
Ana Teresa Moreira Braga Teves Reis
}

\begin{abstract}
Resumo: A limpeza de superfícies pictóricas com sistemas gelificados tem vindo a levantar diversas questões e opiniões contraditórias que se prendem com a deposição de resíduos de alguns componentes dos géis, nomeadamente os surfactantes, nas superfícies tratadas, e com potenciais riscos que ditos sistemas gelificados podem apresentar para os materiais constituintes das pinturas. Propôs-se neste artigo fazer uma revisão generalizada da informação já publicada acerca dos resíduos de géis, numa tentativa de informar outros colegas da profissão acerca deste assunto e assim fomentar tomadas de decisões mais esclarecidas relativamente a uma das operações que mais riscos apresenta para uma pintura: a sua limpeza.
\end{abstract}

Palavras-chave: Conservação; Pintura sobre tela; Limpeza; Sistemas gelificados; Resíduos.

\section{La problemática de los sistemas de residuos gelificados para la limpieza de pinturas}

Resumen: Los sistemas de limpieza de superficies pictóricas con geles han venido planteando diversas cuestiones y puntos de vista conflictivos que se relacionan con la deposición de residuos en las superfícies tratadas, incluso los tensioactivos, y con los riesgos potenciales que los geles pueden presentar para los materiales de las pinturas. Se propone en este artículo una revisión general de la información ya publicada acerca de los residuos de geles, en un intento de informar a otros colegas de la profesión en esta matéria y favorecer así una toma de decisiones más informada por una de las operaciones que presenta más riesgos para una pintura: la limpieza.

Palabras clave: Conservación; Pintura sobre lienzo; Limpieza; Sistemas gelificados; Residuos.

\section{The problematic of residues in gelled systems for cleaning of easel paintings}

\begin{abstract}
The cleaning of pictorial surfaces with gelled systems has been raising various issues and opposite opinions regarding the presence of residues, namely of the surfactants, and whether or not they present any risks to the painting materials. In this article, a general review of the information already published about the residues in gelled systems is proposed, thus attempting to inform other conservators on this subject and encourage clearer decision-making about the operation which most risks presents to paintings, their cleaning.
\end{abstract}

Keywords: Conservation; Easel painting; Cleaning; Gelled systems; Residues.

\section{Introdução}

A utilização de géis em conservação e restauro tem-se revelado um recurso muito útil, nomeadamente nas operações de limpeza. Estes sistemas, introduzidos por Richard Wolbers na década de 80 do séc. XX (Wolbers 2000), permitem prolongar a retenção de uma solução de limpeza limitando, paralelamente, a penetração capilar (o que facilita a limpeza selectiva de camadas). A sua estrutura facilita o controlo da taxa de evaporação dos agentes activos utilizados nas misturas (Khandekar 2004), uma mais-valia no que diz respeito à segurança do operador. Um gel de limpeza é cons- 
tituído por vários produtos e materiais, sendo necessário, em primeiro lugar, a escolha de um agente "activo", que actua quimicamente sobre a superfície (ex. soluções aquosas, solventes, enzimas, agentes quelantes, etc.), misturado com um agente "espessante" em meio aquoso que sustenta o gel (os mais utilizados têm sido os éteres de celulose, como o Klucel $\mathrm{G}^{\circ}$, e os polímeros de ácido poliacrílico - gama Carbopol", 954, 934, 940, 941) e um agente "surfactante" que interage com o espessante para formar o gel (ex. gama Ethomeen', gama Triton ${ }^{\circ} 1$ e Brij $700^{\circ}$ - agentes neutralizantes constituídos por amina polietoxilada e compostos poltoxi alifáticos, respectivamente). No caso de géis aquosos, podem também adicionar-se aditivos, de acordo com as necessidades e especificidades de cada limpeza, como detergentes ${ }^{2}$ que, actuando como tensioactivos, melhoram o contacto com a superfície e removem a sujidade através da formação de micelas e ainda soluçõestampão para regular o nível de pH da mistura (Khandekar 2004).

Desde que se iniciou a aplicação gradual destes sistemas que a comunidade de conservadores e comunidade científica tenta perceber se os resíduos dos componentes não voláteis dos géis (nomeadamente o espessante e o surfactante) podem ser totalmente removidos da camada pictórica e se a ínfima quantidade que permanecer na superfície pode provocar alguma alteração ou patologia nos materiais constituintes da pintura. Neste artigo pretendemos rever os principais estudos científicos realizados nesse sentido ${ }^{3}$, bem como introduzir alguns dos estudos em curso $^{4}$, com o objectivo de sistematizar o "estado da arte" acerca dos resíduos na limpeza com sistemas gelificados, propondo assim metodologias de trabalho actualizadas com os resultados mais recentes.

\section{Os resíduos em sistemas de limpeza gelificados}

O mecanismo de limpeza de vernizes através de solventes e através de sistemas gelificados actua sobre esta camada de modo diferente. Os solventes produzem um inchamento rápido da camada de verniz, seguido de evaporação a vários níveis e a redução ou remoção do verniz é realizada pela remoção do material, em solução absorvida por um cotonete. No caso dos géis aquosos, a presença de sabões produzem a emulsificação do verniz e a acção mecânica do rolar do cotonete intensifica a quebra do filme que é transportado pela estrutura interna do gel (Burnstock e White 1990). Independentemente da eficácia de ambos os sistemas na limpeza de superfícies pictóricas (não se podendo negar as múltiplas vantagens e qualidades da limpeza com géis), o facto de haverem componentes não voláteis neste último traduz-se na deposição de resíduos. Esta acção foi e ainda é objecto de estudo e análise de várias equipas de cientistas e conservadores-restauradores, na procura de consenso ou conclusões acerca da existência de riscos para a obra de arte. Da análise a pinturas limpas com géis entre 1987 e 1999 por GC-MS (Dorge et al. 2004) foi detectada a presença de resíduos de surfactante (Ethomeen ${ }^{\circ}$ ), em concentrações inferiores ao limite de detecção do método analítico $\left(5 \mu \mathrm{g} / \mathrm{cm}^{-2}\right)$ e de ácido poliacrílico (Carbopol ${ }^{\circ}$ ), igualmente em quantidades muito reduzidas. Não se detectaram danos nas pinturas em questão, devendo-se salientar o facto de as mesmas não terem sido envernizadas após este tratamento. $O$ conhecimento empírico demonstra que, se os vestígios do gel não forem totalmente removidos, a superfície ganha um aspecto briIhante e um toque gorduroso, reagindo frequentemente com as camadas de protecção aplicadas posteriormente. Stulik e Wolbers (2004) referem que os componentes utilizados na composição de géis são suficientemente inertes para não prejudicar a camada pictórica limpa, a não ser que um dos componentes entre em decomposição durante o envelhecimento (caso dos surfactantes iónicos, cuja decomposição poderá formar sulfato de hidrogénio de sódio e alterar o pH da superfície) (Dorge et al. 2004). Outros estudos confirmam igualmente que os surfactantes podem levar à alteração dos parâmetros de solubilidade da camada pictórica (Erhardt e Bischoff 1994). 
No que diz respeito à formação de resíduos, de acordo com Stulik e Miller (2004), os resíduos dos géis à base de espessante e surfactante são constituídos principalmente pelo produto da reacção entre esses componentes durante a formação do gel (reacção de neutralização ácido-base), referindo que os vestígios destes materiais iniciam um processo de degradação passadas algumas horas após a sua remoção. Os mesmos autores (2004) concluíram que os surfactantes não iónicos (ex: gama Ethomeen', Triton e Brij’) degradam-se rapidamente, através da formação de componentes altamente voláteis (como o acetaldeído e o glioxal, no caso do Ethomeen $\mathrm{C}-25^{\circ}$ ), não detectáveis através da actual tecnologia analítica (GC-MS). Já as longas cadeias de C18 do Brij $700^{\circ}$ podem provocar uma maior retenção desta substância na superfície da pintura (Carlson e Petersen 2004).

Para se poder obter uma noção comparativa da quantidade de resíduos que podem ficar numa superfície limpa com gel, Stulik e Miller (2004) referem que $100 \mu \mathrm{g}$ de massa de resíduo por $\mathrm{cm}^{2}$, equivalem ao "material externo" que é transferido para a superfície quando se toca com a ponta dos dedos cerca de dez vezes. Stulik e Wolbers (2004) referem que a quantidade média de resíduo depositada sobre uma pintura (antes da remoção de vestígios) é de, aproximadamente, $60 \mu \mathrm{g} / \mathrm{cm}^{2}$.

No que diz respeito a uma possível interferência com os materiais constituintes da pintura, Stulik e Wolbers (2004), referem que, aparentemente, os padrões de decomposição dos surfactantes e dos ligantes são independentes, mesmo após a ocorrência de contacto físico em condições normais. Porém, alertam para o facto de que uma imediata aplicação de camada de protecção poderá abrandar o ritmo destes processos, permanecendo os resíduos entre a camada pictórica e a camada de protecção 5 .

\section{Identificação de resíduos}

Os métodos de exame e análise mais utilizados na identificação de resíduos de géis de limpeza têm sido a microscopia electrónica de varrimento (SEM), a espectrometria de infra-vermelho com transformada de Fourier (FTIR) e a análise por cromatografia gasosa por pirólise e espectrometria de massa (PY-CG-MS). Testes indicam que para verificar a existência de resíduos através de análise por PY-CG-MS, é mais fiável procurar vestígios de agentes surfactantes do que do espessante (em especial o (arbopol ${ }^{\circ}$ ), visto que este, quando transformado em gel não é facilmente identificável, comparativamente com os surfactantes, identificáveis em níveis de concentração de microgramas (Khandekar et al. 2002). Outra técnica inovadora utilizada na identificação de resíduos foi a marcação radioactiva dos materiais constituintes do gel antes da sua aplicação. Este estudo foi iniciado por Richard Wolbers, através da marcação dos surfactantes por rádio-isótopos (Wolbers 1990) (Stulik e Miller 2004). Este método permite quantificar os resíduos de surfactante que ficam depositados sobre uma superfície, bem como qual o método mais eficaz para a sua remoção.

\section{Eliminação de resíduos}

De acordo com Stulik e Wolbers (Dorge et al. 2004), a quantidade de resíduos de gel detectados em qualquer camada pictórica depende da natureza química, da topografia e da porosidade da superfície, já que a maioria das experiências aponta para a possibilidade de eliminação de $99,90 \%$ dos resíduos, se os géis forem aplicados sobre superfícies lisas, macias, inertes, pouco absorventes e pouco porosas (Stulik e Wolbers 2004). A experiência prática reforça a importância da capilaridade e capacidade de absorção do suporte, já que a limpeza de resíduos de géis em obras policromadas com suporte lenhoso revela-se, no geral, mais eficaz. 
Após a revisão de procedimentos e resultados divulgados por diversos investigadores, optou-se por sistematizar alguma da informação recolhida nesses estudos. Burnstock e Miller (Burnstock e Miller 1992) referem que a eliminação de resíduos de sabões de resina à base de ácido abiético e ácido dioxicólico requerem a utilização de um solvente polar (água e/ou saliva) e de um solvente não polar (white spirit) para assegurar a eliminação de todos os resíduos. Nalguns casos será ainda necessária a limpeza com um solvente aromático não-polar (como o xileno). Em relação aos géis aquosos, em princípio, requerem apenas a passagem de água. Estudos mais recentes (Burnstock, 2002) concluem que o método mais eficaz para remover resíduos de um gel é uma primeira limpeza a seco, seguida de passagem com a mistura de solventes utilizada no gel. Outros investigadores (Stulik et al. 2000; Khandekar et al.. 2002; Dorge et al. 2004), tomando como caso de estudo a limpeza de vernizes alterados e analisando uma receita de gel utilizada com frequência (constituída por $2 \mathrm{~g} \mathrm{Carbopol}^{\circ}+20 \mathrm{ml}$ Ethomeen $\mathrm{C}-25^{\circ}+100 \mathrm{ml}$ isopropanol $+10 \mathrm{ml}$ álcool benzílico $+10 \mathrm{ml}$ água desionizada), concluíram que o método mais eficaz para remoção de resíduos deste gel específico é uma primeira limpeza com cotonete seco, seguido de uma limpeza com destilados de petróleo, como o White Spirit ou o ciclohexano (Stulik et al.. 2000). Outros (Khandekar et al.. 2002) demonstram que utilizando este sistema de remoção, após doze horas já não é detectado surfactante, sugerindo que a detecção de resíduos ocorre imediatamente após aplicação, em baixas concentrações, e que diminui num período de tempo relativamente curto, para níveis não detectáveis. Um aspecto importante que requer mais estudos é a questão acerca da necessidade de utilização de solventes para assegurar a remoção dos resíduos dos géis utilizados na limpeza, posteriormente à sua realização, prolongando deste modo a sua acção sobre as camadas da pintura, não eliminando na totalidade o risco de inchamento e lixiviação da superfície pictórica (Burnstock 2002), um dos motivos pelo que a limpeza com géis seria considerada mais vantajosa relativamente à limpeza tradicional com solventes.

\section{Discussão e sistematização de procedimentos: como reduzir a quantidade de resíduos?}

Desde que se iniciou a utilização sistemática desta técnica de limpeza e a investigação acerca da sua eficácia versus desvantagem dos resíduos, que a comunidade científica procura soluções a vários níveis que garantam a inocuidade destes sistemas, nomeadamente no que diz respeito à presença de resíduos. Até que o avanço de técnicas e materiais o permita, os conservadoresrestauradores devem ter presente os riscos que estes sistemas apresentam, contrabalanço a sua relevância para cada caso, e de que modo podem reduzir a deposição de resíduos sobre uma superfície.

As várias investigações revistas atestam que se deve evitar a utilização de géis em superfícies relevadas e texturadas (com empastados, pinceladas evidentes, lacunas, fendas, desníveis, etc.), já que a proporção de resíduos será maior neste tipo de superfícies e de remoção mais complexa, sendo sempre necessário o auxílio de limpeza mecânica (Stulik e Miller 2004). O tipo de superfície mais indicada terá de ser rígido, liso e pouco poroso e quanto mais espesso for o gel, menos resíduo deixará na pintura. Outra questão importante alertada pelos investigadores prende-se com a necessidade de padronização de procedimentos. Já foi comprovado que a eficácia da remoção de resíduos poderá variar entre cada operador numa fracção de 1 para 10 entre várias experiências realizadas (Stulik e Miller 2004).

Recentemente ${ }^{6}$ foram divulgados estudos em curso que revelam avanços e melhorias ao nível de técnicas, metodologias e materiais com vista à redução de resíduos que confirmam a necessidade de validar a utilização prática destes sistemas: 


\section{Aplicação de sistemas gelificados sobre barreiras e géis rígidos}

Três dos principais museus espanhóis (Museu del Prado, Museu Thyssen-Bornemisza e Centro de Arte Moderna Reina Sofia), encontram-se a estudar as propriedades de alguns detergentes, designadamente do Vulpex ', tendo concluído que quando este é aplicado sob a forma de gel líquido (diluído em solvente orgânico com concentrações inferiores a 2,5\%), sobre barreira de papel japonês Sekish $^{\circ}\left(13,5 \mathrm{~g} / \mathrm{m}^{2}\right)$ ou sob a forma de gel rígido, não se observa a deposição de resíduos e o valor de pH mantém-se igual (Ledesma, García e García 2010).

Uma equipa do Stichting Restauratie Atelier Limburg (Holanda) encontra-se a melhorar as técnicas de aplicação de sistemas gelificados no sentido de reduzir o depósito de resíduos. A técnica consiste na aplicação, sobre a camada de verniz, de um tecido-não-tecido ${ }^{7}$ saturado com gel à base de éter de celulose e do solvente escolhido (sem a utilização de surfactante), seguido de sobreposição de um outro tecido absorvente seco e de película Melinex que são levemente pressionados e removidos em conjunto com a primeira camada. Esta técnica reduz a absorção capilar pela camada pictórica, já que a maioria é absorvida pelo papel, e também a acção mecânica na superfície. É necessário, porém, assegurar a eliminação dos resíduos de éter de celulose (Fife et al.. 2010; 2011).

Em Itália, o Cesmar7, tem sido pioneiro no desenvolvimento e utilização de géis rígidos ${ }^{8}$ (tendo como agente activo soluções enzimáticas) na eliminação de resíduos de adesivos hidrófilos utilizados em reentelagens e em consolidações ou fixações, bem como na limpeza de obras muito sensíveis e porosas, como o gesso e os documentos gráficos. (Cremonesi 2010). A utilização de géis rígidos permite a libertação controlada de humidade numa superfície sensível à água para executar tratamentos de limpeza ou para inchar materiais antigos hidrófilos até que seja possível a sua remoção mecânica. Como estes polímeros possuem pouca adesividade, a remoção de resíduos é mais eficaz, desde que a superfície seja lisa. Qualquer solução aquosa pode ser transformada em gel rígido, sendo possível a adição de soluções-tampão, agentes quelantes (como o citrato de triamónio e sódio, utilizados nas misturas de "saliva sintética") e surfactantes, de acordo com o tipo de sujidade a remover (Cremonesi 2010).

\section{Outros métodos}

Encontram-se em desenvolvimento estudos sobre a aplicação de métodos alternativos como a espuma aquosa ${ }^{9}$, tendo-se chegado à conclusão que minimizam a migração de fluidos para o interior da camada pictórica comparativamente à limpeza tradicional com cotonetes, mas que libertam mais água do que os sistemas gelificados, sendo ainda necessário formular e testar composições mais eficazes (Hecknbücker e Demuth 2010). O facto de os resíduos da espuma poderem ser removidos por aspiração, apresenta outra vantagem no que diz respeito à diminuição de abrasão mecânica da superfície pictórica (Hecknbücker e Demuth 2010).

\section{Conclusão}

Existem algumas premissas, comuns a vários investigadores e conservadores-restauradores no que diz respeito à utilização de sistemas gelificados para limpeza de superfícies pictóricas, nomeadamente que deverão ser utilizados quando se prevê a utilização de uma grande quantidade de solvente já que permitem uma redução da toxicidade devido à diminuição da volatilidade e, por outro lado, a utilização de produtos menos tóxicos, devido à possibilidade de aumento de contacto com a superfície e que são sistemas que podem ser ajustados às necessidades de limpeza. Contudo, apesar de ser uma técnica de limpeza com muitas potencialidades, não deverá ser utilizada em todos os casos, sendo necessário avaliar questões como o tipo de sujidade a remover, a textura da 
superfície, o tipo de suporte e a sua capacidade de absorção, factores que podem influenciar o sucesso da operação. Os investigadores que têm vindo a estudar estes sistemas desde o início da sua aplicação transmitem-nos que uma correcta aplicação e remoção dos géis (em superfícies pouco texturadas, pouco danificadas e pouco porosas) garantem a eliminação quase total de resíduos (sendo que estes são constituídos normalmente por quantidades ínfimas de surfactante e de espessante), não se observando até aos dias de hoje quaisquer danos nas pinturas que foram limpas nas décadas de 90 (Stulik, Wolbers in Dorge et al. 2004). Ainda no contexto dessas investigações obtiveram-se outras informações importantes, nomeadamente que a limpeza directa com solventes e misturas de solventes poderá deixar nas superfície uma maior concentração de resíduos de alguns solventes mais comuns, como o Shellsol' (White Spirit), o álcool benzílico e outros hidrocarbonetos de peso molecular elevado e com pontos de ebulição elevados, do que aquela detectadas para os géis (Stulik, Wolbers in Dorge et al. 2004). Encontra-se ainda por estudar se uma aplicação imediata de um verniz após a limpeza poderá retardar a evaporação dos resíduos e qual a interferência entre esta camada, os resíduos e a camada pictórica. Haverá um período mínimo de espera entre a limpeza com géis e a aplicação da camada de verniz?

A quantidade de estudos em curso e o interesse crescente sobre este tema revelam que os profissionais consideram que a utilização de géis em limpeza é uma mais-valia para a eficácia desta operação, esforçando-se por pôr em prática novos métodos que possibilitem a ausência de resíduos. $\mathrm{A}$ comunidade de profissionais ligados à conservação e restauro aguarda novos dados acerca destes estudos, de modo a poder definir metodologias e procedimentos para cada tipo de sujidade a remover.

\section{Notas}

[1] O produto Triton X-100 deixou de ser utilizado com a mesma frequência, devido aos elevados níveis de $\mathrm{pH}(12,5)$ que um potencial resíduo possa transferir para a superfície (Wolbers 1990), pelo seu potencial para formação de peróxidos de éter (Burnstock e White 1990) e pela sua capacidade de mimetizar estrogénio durante a sua decomposição, tornando-o um risco ambiental (Khandekar 2004), nomeadamente para a vida animal.

[2] Entre os sabões comerciais mais utilizados na Europa estão o Vulpex', o C2000 e o Teepol e entre os detergentes estão o Triton X-100 (vide nota 1 ), o Brij $35^{\circ}$ e o Tween $20^{\circ}$.

[3] Um grande avanço no estudo deste tema, foi realizado entre 1997 e 2004, com a publicação de um conjunto de artigos, resultado de pesquisas e experiências efectuadas pelos principais cientistas que até então já se tinham debruçado sobre esta questão, entitulado Surface Cleaning-Gels Research Project. Esta publicação foi promovida pelo Getty Conservation Institute, possibilitando uma visão sobre o "estado da arte" da informação mais actual acerca dos resíduos em limpeza com géis.

[4] A maioria destes estudos foi apresentada na Conferência internacional Cleaning 2010, que decorreu em Valência em Maio do mesmo ano, organizada e coordenada pela Universidade Politécnica de Valência, o Instituto de Restauración del Patrimonio e o Smithsonian Museum Conservation Institute. Aguarda-se a publicação das respectivas actas para se poderem introduzir novos dados das investigações em curso.

[5] Estão ainda por estudar as reacções de uma camada de verniz (ou de protecção) aplicada sobre uma superfície previamente limpa com sistemas gelificados e de que modo a existência de resíduos poderá interferir com futuras limpezas. 
[7] Na 16. Conferência Internacional do ICOM-CC em Lisboa, os autores divulgaram os tecidos-nãotecidos que utilizaram no desenvolvimento desta técnica de limpeza. O material para impregnação é produzido pela marca holandesa Hanotex $\mathrm{BV}^{\circ}$, referência n. ${ }^{\circ} 2516$ - schoonmaakdoek RR e o tecido para a absorção denomina-se Professional Kimtech 7506 e é produzido pela Kimberly-Clark (Fife et. Al. 2011)

[8] Os géis rígidos são constituídos por dispersões aquosas de polímeros à base de polisacarídeos de origem natural, como agarose, agar-agar, phylatel e gellan. Após um processo de aquecimento do sólido e posterior arrefecimento da solução numa temperatura inferior à temperatura de arrefecimento do polímero, as macromoléculas do polímero interagem umas com as outras e reticulam numa estrutura coesa e regular que transporta uma grande quantidade de água que pode ser libertada de um modo controlado (Cremonesi, 2010)

[9] A espuma aquosa é constituída por uma fase líquida e uma fase gasosa, estruturada através da adição de surfactantes e estabilizada pela adição de polímeros (Hecknbücker e Demuth 2010).

\section{Bibliografía}

BURNSTOCK, A. e WHITE, R. (1990). "The Effects of Selected Solvents and Soaps on a Simulated Canvas Painting". Em Cleaning, Retouching and Coatings. Preprints IIC Brussels Congress, 3-7 September 1990. London: International Institute for Conservation of Historic and Artistic Works, 111-18.

BURNSTOCK, A. e LEARNER, T. (1992). "Changes in the surface characteristics of artificially aged mastic varnishes after cleaning using alkaline reagent". Em Studies in Conservation, vol. 37: 165-184.

BURNSTOCK, A. e WHITE, R. (2000). "A preliminary assessment of the aging/degradation of Ethomeen C-12 residues from solvent gel formulations and their potencial for inducing changes in resinous paint media". Em Tradition and Innovation: Advances in Conservation, Preprints of the Contributions to the Melbourne Congress, 10-14 October 2000. London: International Institute for Conservation of Historic and Artistic Works, 34-38.

BURNSTOCK, A. e KIELISCH, T. (2002). "A study of the clearance of solvent gels used for varnish removal of painting" Em Actas do ICOM-CC 13th Triennial Meeting, Rio de Janeiro London: James \& James, 253-262.

CARLSON, J. y PETERSEN, W. (2004). "Aging Characteristics of surfactants". Em Solvent Gels for the cleaning of Works of Art. The Residue Question. Dorge, V. ed. Col. Research in Conservation. Los Angeles: Getty Publications, 84-110.

CREMONESI, P. (2001). L'uso di tensioattivei e chelanti nella pulitura di opere policrome. Col. Collana i Talenti $\mathrm{n}^{\circ}$ 10. Padova: II Prato.

CREMONESI, P. (2009). "Reflexiones sobre la limpieza de las superficies policromadas". Em Unicum, Revista de la Escuela Superior de Conservación y Restauración de Bienes Culturales de Cataluña no 8. Barcelona: ESCRBCC, 48-73. http://unicum.cat/ [Consulta Janeiro 2012].

CREMONESI, P. (2010). "Rigid Gels and Enzyme Cleaning". Em Cleaning 2010. New insights in the cleaning of paintings. (Resumos das comunicações da conferência). Valencia: Universidad Politecnica de Valencia, Smithsonian Museum Conservation Institute, 47-48.

CREMONESI, P. "Modificar las propiedades y la acción del agua y de los disolvente orgánicos, incrementando su viscosidad gracias a los gelificantes". Em Ponencias del Curso de Cremonesi., Grupo Español del IIC. http://www.ge-iic.com/files/Cursos/Cremonesi_Ponencia.pdf . [ConsultaJaneiro 2011].

DORGE, V. (ed.) et al. (2004). Solvent Gels for the cleaning of Works of Art. The Residue Question. Col. Research in Conservation. Los Angeles: Getty Publications. 
ERHARDT, D. e BISCHOFF, J. (1994). "The Roles of Various Components of Resin Soaps, Bile Acid Soaps and Gels, and Their Effects on Oil Paint Films". Studies in Conservation, 39: 3-27.

ERHARDT, D. e TSANG, J. (1991). "Current Research on the Effects of Solvents and Gelled and Aqueous Cleaning Systems on Oil Paint Films". Journal of the American Institute for Conservation, 31, No. 1: 87-94.

FIFE, G., OCH, J., SEYMOUR, K., HOPPENBROUWERS, R. (2010). "Tissue gel composite cleaning at SRAL". Em Cleaning 2010. New insights in the cleaning of paintings (Resumos das comunicações da conferência (Valencia: Universidad Politecnica de Valencia, Smithsonian Museum Conservation Institute, 85-86.

FIFE, G. et al. (2011). "A Package Deal: The development of tissue gel composite cleaning at SRAL". Em Actas do ICOM-CC 16th Triennial Meeting. Lisboa: ICOM-CC, 1-8.

Gels cleaning research Project, Fundação J.P. Getty. http://www.getty.edu/conservation/science/gels/ [consulta Janeiro 2011].

GUERRA, P., ABENI, M. (2008). “Un esempio di applicazione di Gel Rigidi di Agar”. Progetto Restauro, 47.

HECKNBÜCKER, A., DEMUTH, P. (2010). "Surface cleaning with aqueous foams". Em Cleaning 2010. New insights in the cleaning of paintings. (Resumos das comunicações da conferência). Valencia: Universidad Politecnica de Valencia, Smithsonian Museum Conservation Institute, p. 65-66.

IANNUCELLI, S., SOTGIU, S. (2009). "La pulitura superficiale di opere grafiche a stampa com gel rigidi". Progetto Restauro, 49.

KHANDEKAR, N. et al. (2002). "Detection of residues on the surfaces of objects previously treated with aqueous solvent gels". Em Actas do ICOM-CC 13th Triennial Meeting, Rio de Janeiro, 2002. London: James \& James, $352-359$.

KHANDEKAR, N. (2004). "Gelled Systems: Theory and early application". Em Solvent Gels for the cleaning of Works of Art. The Residue Question. Dorge, V. ed. Col. Research in Conservation. Los Angeles: Getty Publications, 5-11.

KHANDEKAR, N. (2004). "Research into Potential Problems Arising from the use of Aqueous Cleaning Systems". Em Solvent Gels for the cleaning of Works of Art. The Residue Question. Dorge, V. ed. Col. Research in Conservation. Los Angeles: Getty Publications, 12-17.

KOLLER, J. (1990). "Cleaning of a Nineteenth-Century Painting with Deoxycholate Soap: Mechanism and Residue Studies". Em Cleaning Retouching and Coatings, Preprints of the Contributions to the Brussels Congress, 3-7 September 1990; Brussels: International Institute for Conservation of Historic and Artistic Works:106-110.

LEDESMA, A., GARCÍA, C., GARCÍA, M. (2008). "Determinación de resíduos del jabón comerical Vulpex empleado en la limpieza de superfícies pintadas jóvenes sin barnizar". Em Actas do Congresso do GEIIC Conservación de Arte Contemporáneo. $9^{a}$ Jornada. Madrid: Museo Nacional Centro de Arte Reina Sofía, 71-82.

LEDESMA, A., GARCÍA, C., GARCÍA, M. (2010). "Effects of commercial soaps on unvarnished painted surfaces. A pilot study for their assessment in Spanish museums". Em Cleaning 2010. New insights in the cleaning of paintings. (Resumos das comunicações da conferência). Valencia: Universidad Politecnica de Valencia, Smithsonian Museum Conservation Institute, 49-50.

MARTínEZ, M.G. Z. (1997). Uso de geles en la limpieza gradual de pinturas sobre lienzo. Col. Científica. Mexico D.F.: Instituto Nacional de Antropologia e Historia.

SEDANO, Ubaldo (dir.) et al. "Sistemas para la eliminación o reducción de barnices. Estudio de residuos. Protocolos de actuación". Museo Thyssen Bornemisza 
http://www.museothyssen.org/pdf/restauracion/proyectos_de_investigacion/sistemas_eliminacion_ES.pdf, [consulta Janeiro 2011].

STULIK, D. et al. (2000). "Surface Cleaning: Quantitative Study of Gel Residue on Cleaned Paint Surfaces". Em Tradition and Innovation: Advances in Conservation, Preprints of the Contributions to the Melbourne Congress, 10-14 October 2000. Melbourne: International Institute for Conservation of Historic and Artistic Works, 188194.

STULIK, D. y MILLER, D. (2004). "Research into Solvent Gel Residues". Em Solvent Gels for the cleaning of Works of Art. The Residue Question. Dorge, V. ed. Col. Research in Conservation. Los Angeles: Getty Publications, 1865.

STULIK, D. y WOLBERS, R. (2004). "Project Outcome, Spin-offs, and Future Research Needs". Em Solvent Gels for the cleaning of Works of Art. The Residue Question. Dorge, V. ed. Col. Research in Conservation. Los Angeles: Getty Publications, 131-144.

WOLBERS, R. (1990). "A Radio-Isotopic Assay for the Direct Measurement of Residual Cleaning Materials on a Paint Film". Em Cleaning Retouching and Coatings, Preprints of the Contributions to the Brussels Congress, 37 September 1990. Brussels: International Institute for Conservation of Historic and Artistic Works, 119-125.

WOLBERS, R. (2000). Cleaning Painted surfaces. Aqueous methods. London; Archetype Publications.

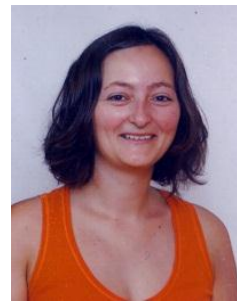

Ana Teresa Moreira Braga Teves Reis

teresa.mbragatevesreis@gmail.com

Ana Teresa Teves Reis (Cascais, 1980), é conservadora-restauradora (Instituto Politécnico de Tomar, 2005) e mestranda em Conservação e Restauro de Bens Culturais (Universidade Católica Portuguesa), cujo contexto proporcionou a realização deste estudo. Exerce actividade profissional como free-lancer desde 2006 e desde 2011 em empresa própria.

Artículo recibido el 30/08/2011

Artículo aceptado el 13/09/2012 